\title{
The Use of Therapeutic Hypothermia in Increased Intracranial Pressure after Traumatic Brain Injury: A Randomized Clinical Trial
}

\author{
Papageorgiou ED ${ }^{1}$, Koukoulitsios $\mathrm{G}^{2}$, Tsikritsaki $\mathrm{K}^{2}$, Sampani AC ${ }^{1}$, Kalantzis ${ }^{2}$ and Androulis Antonios ${ }^{3 *}$ \\ ${ }^{1}$ Department of Nursing, Technological Educational Institution, Greece
}

${ }^{2}$ ICU General Hospital of Athens "G. Gennimatas", Greece

${ }^{3}$ Neurosurgical Department of Medical School of Athens, University General Hospital "ATTIKON", Greece

Submission: April 25, 2017; Published: June 21, 2017

*Corresponding author: Androulis Antonios, Consultant Neurosurgeon, Neurosurgical Department of Medical School of Athens, University General Hospital "ATTIKON”, National and Kapodistrian University of Athens, Greece, Email: a.androulis@gmail.com

\section{Abstract}

Background: Most patients with heavy traumatic brain injury (TBI) are nursed in ICUs. Clinical trials indicate significant mortality and morbidity in cases with sustained increases in intracranial pressure (ICP). A current way of controlling intracranial pressure in ICU is therapeutic hypothermia. The benefit of hypothermia on functional outcome is unclear.

Methods: 26 patients were randomly enrolled in the experimental group and 26 patients in the control group. Patients in the experimental group $(n=26)$ were subjected to therapeutic hypothermia and monitored by 24 hour-recording of temperature and intracranial pressure. In control group ( $n=26), 24$ hours recording of body temperature and intracranial pressure was also performed but without the use of therapeutic hypothermia. Patient recording ranged from 1 to 6 days.

Results There were 1638 hourly measurements of intracranial pressure in the control patient group. ICP exceeded â\%o¥ $15 \mathrm{mmHg}$ in 1192 of these hourly measurements while in remaining 446 values ranged from $8-14 \mathrm{mmHg}$. In experimental group, 2.208 hourly ICP measurements were performed. ICP values exceeded â\% $¥ 15 \mathrm{mmHg}$ in 685 and ranged from $5-14 \mathrm{mmHg}$ in 1523 hourly measurements. The effect of therapeutic hypothermia was found significant $(\mathrm{F}=14.34, \mathrm{p}=0.000)$.

Conclusion: Our investigation showed that therapeutic hypothermia can be used as an additional form of treatment of intracranial hypertension although the benefit in secondary injuries when patient intracranial pressure was â\% $¥ 20 \mathrm{mmHg}$ remains unclear. In particular, in patients with ICP $>20 \mathrm{mmHg}$ after TBI, therapeutic hypothermia does not improve results than the traditional form of care.

\section{Introduction}

$5 \%$ of all deaths in developed societies are due to severe brain injury. In Greece the heavy head injuries due to traffic accidents rank among the top causes of death and permanent disability in all age groups and they are the leading cause by far in the younger ages, particularly from 19 to 25 years of age. Particularly common are the heavy head injuries due to accidents. Every year in Greece, approximately 35,000 people are admitted into hospitals with severe head injuries. It is estimated that 1,600 patients die from them and of course a large number of people with temporary or permanent disabilities should be calculated. Each year in the USA there are 180,000 recorded deaths due to various injuries; 100,000 of them are due to brain injuries [1-3].

In the vast majority of all cases of heavy traumatic brain injuries (75\%), the injured are admitted in Intensive Care
Units, where they are placed in continuous neuro monitoring. Increased intracranial pressure occurs in $50-75 \%$ of severe traumatic brain injury. The treatment of increased intracranial pressure depends on causality and focuses exclusively on the prevention of secondary implications. Secondary hypotensive and hypoxic episodes and episodes of increased intracranial pressure, affect the recovery and outcome of the wounded. Clinical trials indicate significant mortality and morbidity in cases of sustained increases in intracranial pressure. Increased intracranial pressure is therefore an important predictor of adverse outcome indicator.

The modern way of dealing with the increased intracranial pressure in severe injuries in ICU include hypothermia. Hypothermia is defined as a deliberate reduction in patient 
brain temperature down to $32-35^{\circ} \mathrm{C}$ for $12-24$ hours. According to clinical studies, it is used, with increasing frequency, as a therapeutic method to prevent complications or mitigate such patients with brain damage [4-6].

By using therapeutic hypothermia, cerebral oxygen consumption and cerebral metabolic activity are reduced by $45 \%$ and $7.6 \%$ respectively for each reduction in body temperature by $1{ }^{\circ} \mathrm{C}$. Thus, a sufficient supply of oxygen in the brain is ensured, in order to recover the damaged neurons. Moreover, the supply of oxygen in the ischemic regions within the brain is improved, thus reducing the intracranial pressure and, ultimately, the oxygen free radicals, nitric acid, and the amino acids generated during reperfusion after an ischemic episode. These substances act as neurotransmitters and can cause seizures or damage brain cells. The ultimate goal of hypothermia is to improve the morbidity and mortality rates. The aim of the study was to compare the efficacy of hypothermia against the non-implementation of the reduction of intracranial pressure in patients with brain damage.

\section{Methodology \\ Design}

This study was a single-blind, randomized phase II clinical trial with a control group. This is equal randomization (1:1) with two study groups. It was conducted on a small number of people and the aim was to investigate the safety of therapeutic hypothermia towards the reduction intracranial pressure value. After the target population had been defined, the criteria for inclusion and exclusion of individuals in the study were set. The study was conducted in Athens, capital of Greece, from April 2016 to July 2016.

\section{Population-Sample}

The study sample consisted of patients with brain injuries admitted to the Intensive Care Unit (tertiary health care) of GNA "G. Genimatas ". By setting a two-sided significance level of 5\% and a power of $80 \%$, taking into account a projected loss of $10 \%$, a sample size of 30 patients per group was necessary. Patients were classified randomly following simple randomization procedures (random numbers from the book imports) in both groups. 26 patients were randomly enrolled in the experimental group and 26 patients in the control group. In the experimental group 24 recordings of the 26 patient's temperature with simultaneous recordings of intracranial pressure camino and application of therapeutic hypothermia were performed. In the control group there were also 24 thermometry and simultaneous recordings of the body temperature values and the intracranial pressure using camino but without the use of therapeutic hypothermia. The time to record the above values ranged from 1 to 6 days. The initial contact was made with the link nurse who worked in the ICU and his / her supervisor / Head of ICU to clarify the purpose of the study and set by the head contact person with the interviewer. An independent Data Monitoring Committee (Data Monitoring Committee) reviewed the data for patient safety, while some interim analysis was not carried out on the efficacy or futility of therapeutic intervention.

The suitable participants were all adults aged 18 years or more. Specifically, patient inclusion criteria were:
A. $\quad$ G.C.S $\leq 8$.
B. ICP $>15 \mathrm{mmHg}$
C. Patients with the following neurological damage:
i. Epidural / subdural hematoma
ii. Subarachnoid hemorrhage
iii. Intracerebral hematoma
iv. Cerebral contusions
v. Cerebral edema
vi. Axotomy
vii. Intraventricular hematoma

Exclusion criteria were:

A. Deceased patients

B. Patients under 18 years

\section{Ethical issues}

The study was carried out, after there had been a request to the Scientific Council of the hospital for permission to conduct research and approval obtained.

\section{Intervention teams}

The sequence distribution concealed from investigators who introduced and evaluated participants. That was in order to prevent the prediction of the classification of the therapeutic approach, so to protect those who enrolled as participants from the influence of such knowledge. The outcome assessors and data analysts remained blinded during distribution.

To measure body temperature in the bottom third of the esophagus, a method quite reliable in ICU patients was used, because the temperature value obtained represents the body's core temperature. Intraventricular fiber optic camino type catheters, which allow the CSF drainage and monitoring the dynamic behavior of intracranial pressure, were used. Demographics and measurements were recorded on a special form (age, sex, temperature hourly intracranial pressure per hour input cause, method of application side) [7-10].

\section{Outcomes}

The primary endpoint was the improvement in the percentage of patients achieving the return of intracranial pressure to normal levels. The secondary outcome, but equally important was the reduction of damage from brain damage.

\section{Statistical analysis}

For data analysis used the Statistical Package for Social Sciences (SPSS) version 22.0. For the investigation of the design variables descriptive statistics were used, based on which the frequency of the mean value (MV) and the standard deviation 
$( \pm T A)$ variables reported. The significance level was set at a level $\leq 0.05$. For the main final outcome analysis of variance (ANOVA) and control was used while for the secondary endpoints, the Scale of Glasgow and mortality at 6 months after the injury [1013].

\section{Results}

\section{Show the flow of participants in diagram}

52 patients were appropriate, due to their age participants, for the study. The flow chart below specifies how many participants were divided into two groups, those who remained in the study until its completion or if some were excluded before the study completion (Intention to treat analysis) (Figure 1).

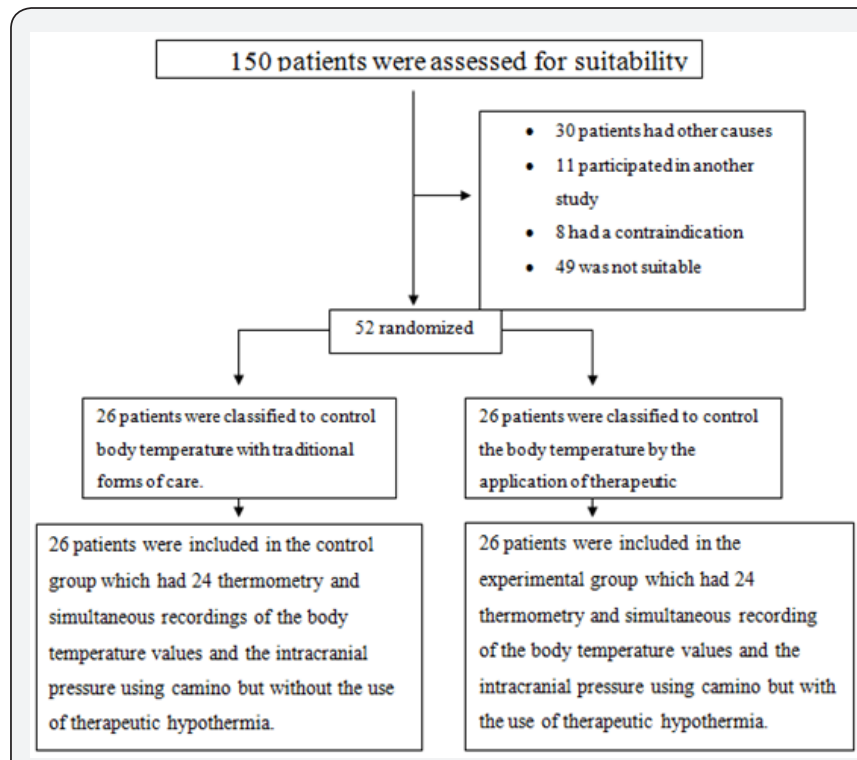

Figure 1: Flow diagram of a test measurement of therapeutic hypothermia in patients with increased intracranial pressure after brain injury against the non-implementation of therapeutic hypothermia.

\section{Demographics}

In the control group included 13 men and 13 women. The age ranged from 22-69, with a mean of 49 years. All patients had brain contusions and cerebral edema. The values of intracranial pressure ranged from 8 to $26 \mathrm{mmHg}$.

The majority of the experimental group of patients were males $(n=20)$. The age ranged from 24-69, with a mean of 45 years. All patients had brain contusions and cerebral edema. The values of intracranial pressure ranging from 5 to $26 \mathrm{mmHg}$. The proportion of patients who experienced any side effects differed significantly between the two groups. The demographic and clinical characteristics of the 2 groups are shown in Table 1. Regarding the patients in the control group, there were 1638 hourly measurements of intracranial pressure. The value $\geq 15 \mathrm{mmHg}$ was evident in 1192 hourly measurements. In other hourly measurements (446), the values of ICP ranged from 8-14mmHg. In the experimental group of patients, there were 2,208 hourly measurements of intracranial pressure. The value of $\geq 15 \mathrm{mmHg}$ was evident 685 hourly measurements. In other hourly measurements (1523), the intracranial pressure values ranged from 5 - $14 \mathrm{mmHg}$.

Table 1: Demographic and clinical characteristics.

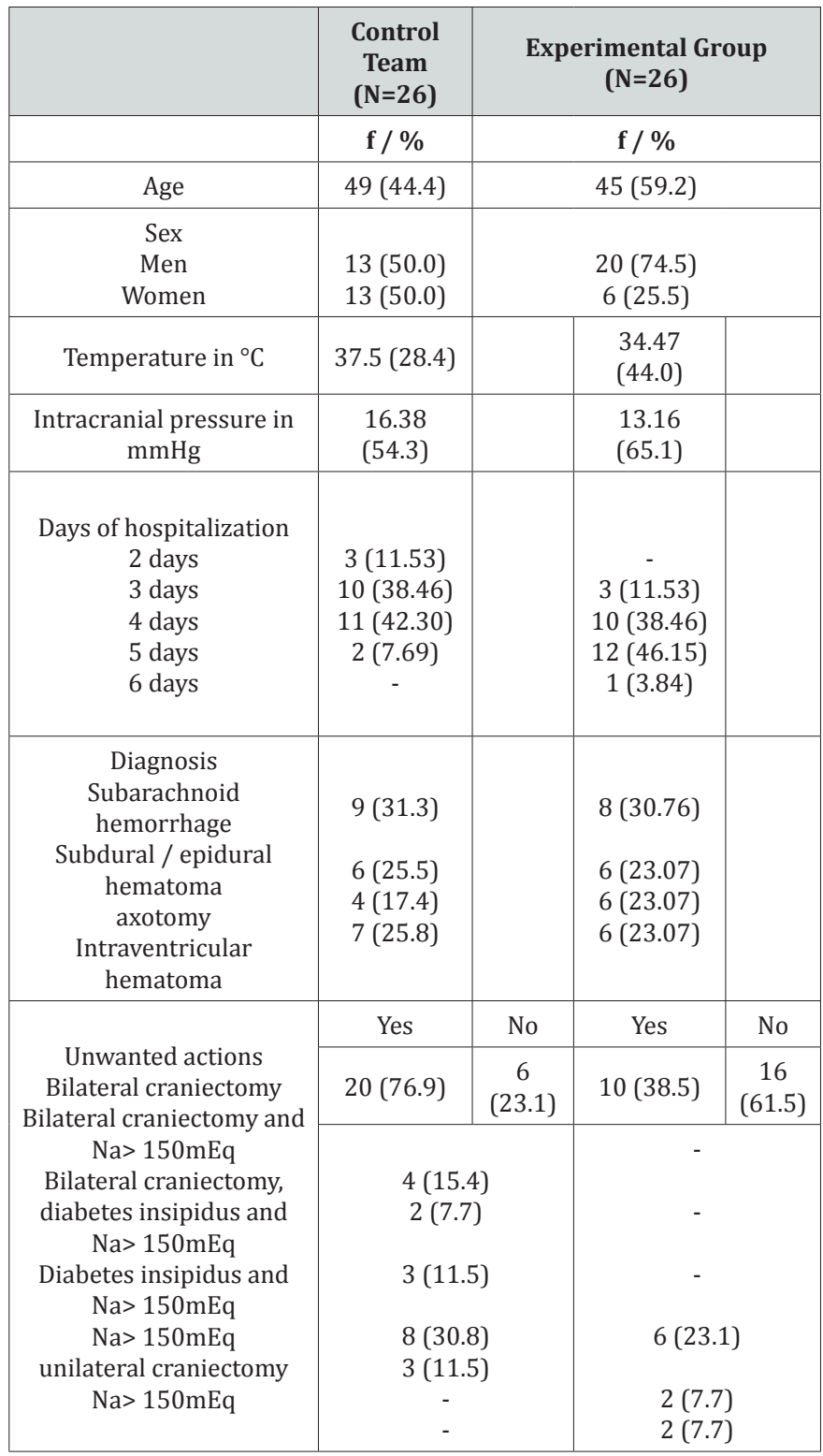

\section{Control group T-test}

The Levene test for equality of fluctuations in the case of the control group reported that the variations are equal, because the price of $0.790 \mathrm{p}$ probability is not statistically significant. The average price of intracranial pressure for women $(M=16.55$, $\mathrm{SD}=2.98)$ was higher $(\mathrm{t}=-2.29$, two-tailed $\mathrm{p}=0.022)$ than the average for men $(M=16.20, S D=3.22)$ [14-16].

\section{Intervention group T-test}

Levene test for equality of fluctuations in the case of the experimental group indicates that the variations are equal, because the price of $0.686 \mathrm{p}$ probability is not statistically significant. The average price of intracranial pressure women $(M=13.62, S D=3.00)$ higher $(t=-3.96$, two-tailed $p=0.000)$ than the average for men $(M=13.01, S D=3.18)$. 


\section{One-way ANOVA}

Calculations of the simple non-correlated analysis of variance (ANOVA) were made and found that the effect of therapeutic hypothermia was generally significant $(\mathrm{F}=14.34, \mathrm{p}=0.000)$.

\section{Discussion}

Potential limitations of our study may be related to the small sample of patients as well as access to the ICU in a hospital. As the intervention was implemented for both sexes, for all ages, in patients with focal and diffuse brain damage, the results indicate that all patients will benefit from the use of therapeutic hypothermia for the reduction of intracranial hypertension. Patients participating in the study suffered from focal and diffused brain damage. Focal damage, is caused by a direct blow to the head as in a fall (contusion, rupture of brain tissue and creation of bleeding or hematoma in the epidural, subdural, subarachnoid and intracerebral space). Diffused damage is indirectly caused by sudden movement of the head that is great acceleration or deceleration, such as in traffic accidents. The clinical spectrum ranges from a simple concussion until prolonged traumatic coma, known as diffuse damage to axons (diffuse axonal injury). This trial showed that the use of therapeutic hypothermia was effective in reducing intracranial pressure and consequently led to a reduction of secondary lesions. Patients with partial lesions showed good recovery and moderate disability as defined by the Glasgow Coma Scale (5-9) and mortality after 6 months. Patients with diffused brain lesions had a higher mortality rate. The conclusion that is consistent with a survey conducted in Japan in the years 2002 to 2009. Assays (analyses) were performed in 135 patients (88 treated with therapeutic hypothermia and 47 with control fever). Clinical outcomes were assessed with the Glasgow outcome scale and mortality at 6 months after the injury. The results were favorable in young patients $(<=$ 50 ) by evacuation of traumatic brain mass, which significantly increased from $33.3 \%$ to the simple control of fever in $77.8 \%$ with therapeutic hypothermia. However patients with diffuse injury treated with therapeutic hypothermia, had significantly higher mortality than patients treated with a single disease control. In conclusion to this research, control of intracranial pressure with therapeutic hypothermia was difficult in patients with diffused injuries, but hypothermia was effective for young patients with traumatic brain mass evacuation. Additionally, a retrospective multi-parameter monitoring study conducted in 14 patients with TBI, who were hospitalized in the Intensive Care Department of Neurosurgery of Burdenko Institute for 20102013, showed that hypothermia is an effective method for the correction of intracranial hypertension. Also a survey conducted in Edinburgh Hospital collected data from 17 patients with intracranial pressure more than $20 \mathrm{mmHg}$. The conclusion of the survey was that therapeutic hypothermia is an effective tool for managing intracranial hypertension and could potentially reduce the number of hyperosmolar therapies required. It remains unclear whether the use of therapeutic hypothermia, achieves the reduction of intracranial pressure in patients after TBI.

In our investigation showed that therapeutic hypothermia can be used as an additional form of treatment of intracranial hypertension but to ensure the avoidance of secondary injuries when the patient had intracranial pressure $\geq 20 \mathrm{mmHg}$. In research conducted and involved 387 patients in 47 centers in 18 countries in November 2009 until October 2014, randomly selected adult patients with intracranial pressure higher than 20 $\mathrm{mm} \mathrm{Hg}$. The conclusion of the study was that in patients with intracranial pressure above $20 \mathrm{~mm} \mathrm{Hg}$ after traumatic brain injury, therapeutic hypothermia to reduce intracranial pressure does not lead to better results than the traditional form of care.

\section{References}

1. Dietrich WD, Helen M (2015) Therapeutic hypothermia and targeted temperature management in traumatic brain injury: Clinical challenges for successful translation. Brain res1640(1): 94-103.

2. Polderman KH, Herold I (2009) Therapeutic hypothermia and controlled normothermia in the intensive care unit: Practical considerations, side effects, and cooling methods. Crit Care Med 37(3): 1101-1120.

3. https://www.intensivecare.com.cy/teleprometheus/index.php/ leksiko/117-th/287-therapeutiki-ypothermia

4. Polderman KH (2008) Induced hypothermia and fever control for prevention and treatment of neurological injuries. Lancet 371(9628): 1955-1969.

5. Stocchetti N, Maas AI (2014) Traumatic intracranial hypertension. N Engl J Med 370(10): 972.

6. European facts and the Global status report on road safety 2015-WHO

7. https://www.intensivecare.com.cy/teleprometheus/index.php/el/ leksiko/119-k/202-kranioegkefaliki-kakosi

8. Nikolov, Nikolay M, Anthony J (2003) Mild therapeutic hypothermia to improve the neurologic outcome after cardiac arrest. Survey of Anesthesiology 47(4): 219-220

9. Cardiological intensive care unit. General Hospital Konstantopoulio, Therapeutic hypothermia after cardiac arrest.

10. Suehiro E, Koizumi H, Fujisawa H, Fujita M, Kaneko T, et al. (2015) Diverse effects of hypothermia therapy in patients with severe traumatic brain injury based on the computed tomography classification of the traumatic coma data bank. J Neurotrauma 32(5): 353-358.

11. Oshorov AV, Popugaev KA, Savin IA, Lubnin AY, Gavrilov AG, et al. (2013) The use of intravascular hypothermia to correct intracranial hypertension in patients with severe traumatic brain injury. Zh Vopr Neirokhir Im N N Burdenko 78(5): 41-7.

12. Flynn, Liam MC, Jonathan Rhodes, Peter JD (2015) Therapeutic hypothermia reduces intracranial pressure and partial brain oxygen tension in patients with severe traumatic brain injury: preliminary data from the Eurotherm3235 Trial. Ther Hypothermia Temp Manag 5(3): 143-151.

13. Andrews PJ, Harris BA, Murray GD (2015) Hypothermia for intracranial hypertension after traumatic brain injury. N Engl J Med 374(14): 1385.

14. Marion DW (2001) Therapeutic moderate hypothermia and fever. Curr Pharm Des 7(15): 1533-1536. 
15. Kalatzis, Ilias, Andreas Karabinis, Dimitrios E (2009) Papageorgiou Induced Therapeutic Hypothermia in Intensive Care Patients with Craniocerebral Injury. Nosileftiki 48(2).

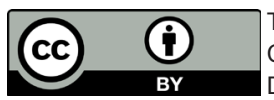

his work is licensed under Creative Commons Attribution 4.0 Licens

DOI: 10.19080/OAJNN.2017.04.555637
16. Urbano LA, Mauro Oddo (2012) Therapeutic hypothermia for traumatic brain injury. Current neurology and neuroscience reports 12(5): 580-591.

Your next submission with Juniper Publishers
will reach you the below assets
- Quality Editorial service
- Swift Peer Review
- Reprints availability
- E-prints Service
- Manuscript Podcast for convenient understanding
- Global attainment for your research
- Manuscript accessibility in different formats
( Pdf, E-pub, Full Text, Audio)
- Unceasing customer service
Track the below URL for one-step submission
https://juniperpublishers.com/online-submission.php

